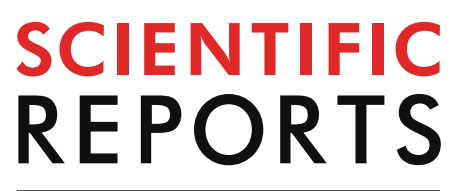

natureresearch

Check for updates

\title{
Applicability of care quality
} indicators for women with low-risk pregnancies planning hospital birth: a retrospective study of medical records

\author{
Kayo Ueda ${ }^{1,2 \bowtie}$, Toshiyuki Sado ${ }^{3}$, Yoshimitsu Takahashi ${ }^{1}$, Toshiko Igarashi ${ }^{2} \&$ \\ Takeo Nakayama ${ }^{1}$
}

Practices for planned birth among women with low-risk pregnancies vary by birth setting, medical professional, and organizational system. Appropriate monitoring is essential for quality improvement. Although sets of quality indicators have been developed, their applicability has not been tested. To improve the quality of childbirth care for low-risk mothers and infants in Japanese hospitals, we developed 35 quality indicators using existing clinical guidelines and quality indicators. We retrospectively analysed data for 347 women in Japan diagnosed with low-risk pregnancy in the second trimester, admitted between April 2015 and March 2016. We obtained scores for 35 quality indicators and evaluated their applicability, i.e., feasibility, improvement potential, and reliability (intra- and inter-rater reliability: kappa score, positive and negative agreement). The range of adherence to each indicator was $0-95.7 \%$. We identified feasibility concerns for six indicators with over $25 \%$ missing data. Two indicators with over $90 \%$ adherence showed limited potential for improvement. Three indicators had poor kappa scores for intra-rater reliability, with positive/negative agreement scores $0.94 / 0.33,0.33 / 0.95$, and $0.00 / 0.97$, respectively. Two indicators had poor kappa scores for inter-rater reliability, with positive/negative agreement scores $0.25 / 0.92$ and $0.68 / 0.61$, respectively. The findings indicated that these 35 care quality indicators for low-risk pregnant women may be applicable to real-world practice, with some caveats.

No serious differences in clinical outcomes such as infant mortality and morbidity have been reported among low-risk pregnant women giving birth at home, in a midwifery unit, or in an obstetrics unit ${ }^{1-5}$. However, childbirth care practices for women with low-risk pregnancy vary according to birth setting, medical professional, and organizational system. Women with low risk who are planning a birth at home or in a midwifery unit are more likely to have a vaginal birth and to receive less unnecessary medical intervention than women with planned births in an obstetrics unit ${ }^{6}$. In addition, women receiving midwife-led continuous care by the same midwife or team of midwives from pregnancy until the early parenting period report greater satisfaction ${ }^{7}$. In all cases, it is critical to refrain from unnecessary interventions, such as caesarean sections and episiotomies ${ }^{8-10}$.

To improve quality of care, quality indicators have been widely used in many clinical fields. A quality indicator is defined as "a measurable element of practice performance for which there is evidence or consensus that it can be used to assess the quality, and hence change in the quality, of care provided"11,12. Quality indicators for maternal and perinatal hospital care have been developed mainly for high-risk pregnancy using the consensus method $^{13-16}$.

\footnotetext{
${ }^{1}$ Department of Health Informatics, Kyoto University School of Public Health, Yoshida Konoe-cho, Sakyo-ku, Kyoto 606-8501, Japan. '2Department of Nursing Women's Health and Midwifery, Faculty of Nursing, Nara Medical University School of Medicine, 840 Shijo-cho, Kashihara, Nara 634-8521, Japan. ${ }^{3}$ Department of Obstetrics and Gynecology, School of Medicine, Nara Medical University, 840 Shijo-cho, Kashihara, Nara 634-8521, Japan. ${ }^{\varpi}$ email: veda.kayo.85a@st.kyoto-u.ac.jp
} 
In Japan, $98 \%$ of women give birth in hospitals ${ }^{17}$, where midwife-led continuous care for low-risk woman is monitored by obstetricians. Among midwives, $87 \%$ of midwives works at hospital and clinics ${ }^{18}$. Midwives in Japan are not legally allowed to perform interventions such as episiotomy, epidural anaesthesia, oxytocin infusion, and instrumental delivery. If necessary, obstetricians from the same hospital provide emergency care. Additionally, care for low-risk pregnancy and childbirth is not covered by insurance in Japan; thus, there are no healthcare claims issued for these types of care. Clinical practices that are covered by the national insurance system can be administratively monitored using claims data; however, data for these low-risk pregnancies are neither publicly accumulated nor evaluated. Types of care that are not included in a claims database have not been adequately investigated with respect to quality improvement. To improve this situation and make such care more accessible, we focused on the importance of clinical data that are available from medical records, as the best method for quality improvement in each medical facility. Under this background, to assess the quality of childbirth care provided for women with low-risk pregnancy who give birth in a hospital, we developed and updated care quality indicators using existing clinical practice guidelines and quality indicators ${ }^{19,20}$. We aimed to demonstrate the applicability of care quality indicators for planned hospital births among women with lowrisk pregnancies in Japan.

\section{Methods \\ Study design. This was a retrospective study of medical records.}

Study setting and participants. The study was conducted in one urban and one suburban hospital in Japan. Both hospitals have a perinatal medical centre. A perinatal medical centre is a key facility that provides perinatal and postnatal care to the surrounding area. The facilities contained units and teams that could treat serious illness in an emergency. One hospital was affiliated with a university; the other was a private general hospital. As both hospitals have a midwifery unit and an obstetric unit in the same ward, low-risk pregnant women can select midwife-led continuous care or obstetrician-led care from pregnancy to afterbirth. Low-risk pregnancy has no widely accepted definition. In our previous articles, we have defined low-risk pregnancy as "a pregnant woman with no particular high-risk factors or complications" 19,20 . For women who plan to give birth in a midwifery unit and have had at least three prenatal check-ups during each trimester, obstetricians diagnose abnormalities in the woman or the infant. If necessary, emergency care is provided by obstetricians in the same hospital. Low-risk pregnancy in this setting is also defined as a pregnant woman with no particular high-risk factors or complications ${ }^{20}$.

Using a retrospective medical records review, we collected data on women admitted for delivery in the participating hospitals during the study period of April 1, 2015 to March 31, 2016. The inclusion criteria were as follows: determined to have a low-risk pregnancy during the second trimester, and selection of planned hospital birth and midwife-led continuous care from pregnancy until the early parenting period in a midwifery unit. The exclusion criteria were as follows: aspects or complications of high-risk pregnancy such as multiple pregnancy and premature birth $<37$ weeks' gestation, elective caesarean section before the onset of labour, no antenatal care, or declined to participate in this study. This study used only past medical record. According to the current Ethical Guidelines for Medical and Health Research Involving Human Subjects in Japan and the Declarations of Helsinki, we made our study to be open by posting information in the participating hospitals. This study, with the procedure of waiving individual consent, was approved by the Ethics Committee of Kyoto University Graduate School Faculty of Medicine (No. R0442), the Ethics Committee of Morinomiya University of Medical Sciences (No. 2015-29), and the Ethics Committee of Nara Medical University (No. 1269).

Outcome and evaluation. Quality indicator scores. The quality indicators used in this study were developed by a multidisciplinary team of healthcare professionals and lay mothers, using the RAND/UCLA appropriateness method in $2012^{19}$. These indicators are focused on process and outcome indicators. Based on new or updated clinical practice guidelines, the quality indicators were updated using modified Delphi methods in 2016, resulting in 35 quality indicators ${ }^{20}$. The care quality indicators for women with low-risk pregnancies who planned to give birth in a hospital are listed in Table 1.

We calculated individual indicator scores using a dichotomous variable with values of 0 or 1 for each participant and each indicator. We calculated the percentage of adherence for each indicator as following equation:

Number of participants eligible for indicator and receiving recommended or non-recommended care

Number of participants eligible for indicator excluding those with an obvious reason not to undergo the process, as defined by the indicator (\%)

We analysed the data for clinical assessment of each indicator at the participant level.

Evaluation criteria for applicability. We conducted a practical test of multifaceted applicability using the three criteria of feasibility, improvement potential, and reliability ${ }^{21-23}$. (1) Feasibility signifies the extent to which the required data are easily available or can be collected without burdening staff. (2) Improvement potential is the sensitivity to detect when medical performance has changed, to discriminate among and within subjects. (3) Reliability relates to how well the measure is defined and how precisely it is specified so that it can be consistently implemented by the same or different data collectors. To assess the reliability of quality indicators in this study, the inter- and intra-rater reproducibility was examined.

(1) Feasibility

An indicator was considered "unfeasible" if $>25 \%$ of participants (denominator) for an indicator score could not be included because of missing data ${ }^{24}$. 


\section{Antepartum}

$1 \quad$ Primipara who has enrolled in a childbirth class about antenatal care $1 \quad$ and delivery by 36 weeks gestation

\begin{tabular}{l|l}
\hline 2 & Discussed a birth plan
\end{tabular}

Woman receiving antibiotic prophylaxis during childbirth if maternal

3 group B streptococcus infections are identified at 33-37 weeks' gestation

\section{Intrapartum}

Initial assessment of labour risk at admission: (1) measuring foetal heart rate more than $20 \mathrm{~min}$, (2) vaginal examination, (3) frequency

4 of construction, (4) woman's emotional and psychological needs, (5) a part and level of pain including her desire for pain relief, (6) foetal movement

Assessment during first stage labour: (1) 8-hourly temperature and blood pressure, (2) half-hourly frequency of contractions and foetal

5 heart rate, (3) vaginal examination 4-hourly or if there is concern about progress or in response to the woman's wishes, (4) woman's emotional and psychological needs, including her desire for pain relief Assessment during second stage labour: (1) 1-hourly blood pressure and woman's heart rate, (2) half-hourly frequency of contractions, (3) half-hourly foetal heart rate, (4) frequency of passing urine, (5) vaginal examination 1-hourly or if there is concern about progress or in response to the woman's wishes, (6) woman's emotional and psychological needs

$7 \quad$ Women planning spontaneous vaginal birth in a midwifery ward, and being able to follow that plan

8 Women with a term, singleton infant in vertex position delivered by 8 caesarean section

9 Women with a term, singleton infant in vertex position delivered by vaginal delivery

10 Women with a term, singleton infant in vertex position delivered by instrument delivery

11 Women with a term, singleton infant in vertex position delivered by labour induction

12 Term infants with Apgar score less than 7 at 5 min after birth

13 Living infants with birth injuries

Respiratory support: Resuscitation for asphyxiated term neonate with 14 low oxygen concentrations and oxygen saturation measured by pulse oximetry immediately after birth

Infants offered the necessary resuscitation in the first minutes after

15 birth, evaluating their condition in line with the Japanese Neonatal Resuscitation Algorithm

16 Women having early skin-to-skin contact with their babies if they wish, soon after birth in secure surroundings

17 Women having been encouraged and supported to adopt the most comfortable positions throughout second stage labour

18 Women with perineal tear and no perineorrhaphy

19 Second degree perineal laceration

20 Third or fourth degree perineal laceration

21 Postpartum haemorrhage more than $500 \mathrm{~g}$ within $2 \mathrm{~h}$ of birth

22 Women receiving uterotonics for the prevention of postpartum haemorrhage during the third stage of labour

Postpartum: 1 week after childbirth

\begin{tabular}{l|l|l}
\hline 23 & Infants admission to paediatrics department within a week after birth & Lower
\end{tabular}

24 Infants that were fed only breast milk at the time of discharge from the hospital

Infants given formula supplementation without medical rationale

25 from birth to discharge in term infants, even though the woman intended to breastfeed

26 Peer review of severe adverse events with medical staff

27 Women having a fall during their hospitalization

28 Women having a review of their childbirth experience and support with the midwives and other staff who assisted at the birth

29 Women switched to receive care provided primarily by obstetricians from midwifery ward

Women received cessation counselling intervention (including guid-

30 ance on smoking cessation) if identified as either a tobacco user or passive smoker

Higher

Higher

Higher

Higher

Lower

Lower

Lower

Lower

Lower

Lower

Higher

Lower

Higher

Lower

Higher

\begin{tabular}{|l|l|}
\hline Higher & \\
\hline Higher & \\
\hline Higher & \\
\hline
\end{tabular}

Women admitted during first labour

Women admitted during second labour

Higher

Labour induction, instrument delivery or Kristeller manoeuvre

Higher

Higher

Infant death

The methods other than using uterotonics

Intrauterine foetal death before starting labour

Women didn't desire early skin-to-skin contact. Women or infants

Higher

didn't meet the criteria of early skin-to-skin contact care

Women or infants stopped early skin-to-skin contact care

Higher

A case where the safety for a infant cannot be ensured

Caesarean section

Caesarean section

Caesarean section

Caesarean section

Caesarean section

Infants with antenatally congenital anomalies

Infants admitted to paediatrics department or needed to supply

formula with medical evidence

Infants admitted to paediatrics department or needed to supply formula with medical evidence

Women transported to or from the other hospital 


\begin{tabular}{|l|l|l|l|}
\hline No & Theme of indicator & Direction for improvement & Excluding criteria of target subject \\
\hline 31 & Infants administered vitamin K three times by one month after birth & Higher & Infants admitted to paediatrics department \\
\hline 32 & $\begin{array}{l}\text { Infants who had been fed only breast milk at the time of the health } \\
\text { examination for children of } 1 \text { month of age }\end{array}$ & Higher & $\begin{array}{l}\text { Infants admitted to paediatrics department or needed to supply } \\
\text { formula with medical evidence }\end{array}$ \\
\hline 33 & Women or infants readmitted within 30 days of discharge & Lower & $\begin{array}{l}\text { Women having mental health disorders during pregnancy. Infant } \\
\text { death }\end{array}$ \\
\hline 34 & $\begin{array}{l}\text { Women being screened for antenatal or postnatal depression using a } \\
\text { validated questionnaire }\end{array}$ & Higher & Women having mental health disorders before pregnancy \\
\hline 35 & $\begin{array}{l}\text { Women and infants having complete medical records based on all } \\
\text { quality indicator }\end{array}$ & Higher & Women and infants admitting within 24 h \\
\hline
\end{tabular}

Table 1. List of original 35 care quality indicators. "Higher" means that the quality of care in the facility is better when there is a high proportion of patients who received the intervention among the group who would benefit from it. "Lower" means that the quality of care is better when there is a low proportion of patients with negative events among the group who should receive this care.

(2) Improvement potential

An indicator was considered "low opportunity for quality improvement (or low sensitivity to change)" if the indicator score percentage was $\geq 90 \%{ }^{24,25}$.

(3) Reliability

To assess the intra-rater and inter-rater reliability, we randomly sampled the medical records of 20 mothers from each of the two hospitals $(n=40)$. A researcher $(\mathrm{KU})$ explained the procedure to the two raters (MT, NN). After completing several training sessions, they independently measured the quality indicators twice a month. The intra-rater and inter-rater reliability was evaluated by two research assistants (MT, NN) by measuring data from the records of selected 20 mothers from each hospital. In parallel, two midwives working at each hospital evaluated 10 records. We primarily used the kappa coefficient and secondarily used agreement score (positive and negative agreement score ${ }^{26}$ ) (Supplementary information 1). The kappa coefficient criteria were as follows: $<0.40$, poor; $0.40 \leq \kappa \leq 0.60$, moderate; $0.60<\kappa \leq 0.80$, good; and $>0.80$, very good $)^{27}$. We also determined the percentage of positive and negative agreement for each indicator. The median, minimum, and maximum score for both agreements in terms of intra-rater and inter-rater reliability were also calculated.

Data sources and measurement. We retrospectively identified eligible mothers from the clinical records using medical safety and management reports. One researcher (KU) and seven midwives (four of whom worked at the participating hospitals and three who were research assistants) collected the data. The midwives had more than 3 years' work experience and had received training in data collection. They manually collected indicatorrelevant data for women and infants from the records and entered them into an electronic data capture system $(\text { REDCap })^{28}$. We used the data to evaluate the performance of planned hospital birth care for women with lowrisk pregnancy. The research assistants measured intra-rater reliability. Inter-rater reliability data for research assistants and midwives working in the participating hospitals were collected more than 1 month after the initial measurement.

Sample size. We assumed an indicator adherence of 50\% (the largest number of medical records or participants needed for adherence) with a confidence level of $95 \%$ and a precision estimate of $7.5 \%$ and included 167 participants. Multiple facilities were set up to obtain 167 participants per hospital ${ }^{29}$. We randomly selected sample records to assess the reliability of over $10 \%$ of the total participant records ${ }^{24}$.

Statistical analysis. We defined missing data as data not recorded in the clinical records. We performed statistical analysis using JMP ${ }^{\circledast}$ Pro, version 14.0 (SAS Institute, Cary, North Carolina, USA).

\section{Results}

Participants. Of 388 eligible participants, we analysed data for 347 mothers. A flow chart showing participant selection is shown in Fig. 1.

Table 2 shows the characteristics of participating women and infants. The median age for women was 31 years and the median gestational age was 39 weeks. There were 201 multiparous women (58\%) and no foetal or neonatal deaths.

Quality indicator scores. The scores for each quality indicator are shown in Table 3. The range of adherence to all indicators was $0-95.7 \%$. Of 24 applicable indicators, the highest score $(79.5 \%, 276 / 347)$ was found for no. 9 (vaginal delivery). No. 26 (staff peer review of severe adverse events), no. 34 (screening for antenatal or postnatal depression), and no. 35 (having complete medical records based on all quality indicators) had the lowest scores $(0 \%)$. The mean score for all indicators was $32.6 \%$.

Feasibility. There were six indicators with feasibility concerns: no. 14 (neonatal respiratory support); no. 15 (necessary resuscitation in the first minutes after birth); no. 26 (staff peer review about severe adverse events); no. 28 (having a review of the childbirth experience and support from midwives); no. 30 (mother smokes or receives 


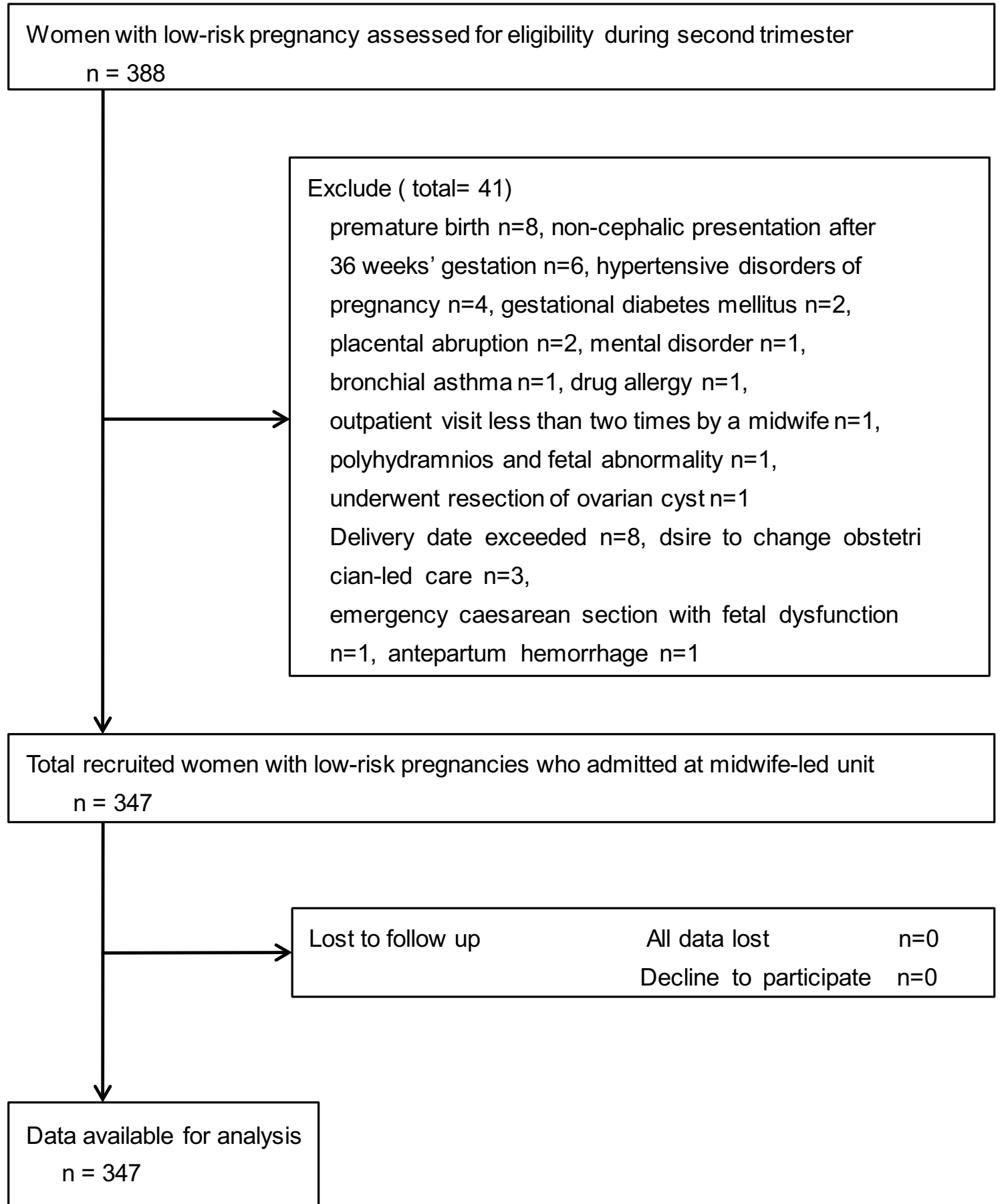

Figure 1. Flow chart for selecting participants.

passive smoking cessation counselling); and no. 31 (administration of vitamin $\mathrm{K}$ three times up to 1 month after birth). At the time of data extraction, $>25 \%$ of the participants had missing data for these indicators.

Improvement potential. Two indicators showed a low opportunity for improvement (indicator score $\geq 90 \%$ ): no. 3 (receiving antibiotic prophylaxis during childbirth if the mother had a group B streptococcal infection) and no. 4 (initial assessment of labour risk on admission).

Reliability. Table 4 shows the reliability for each quality indicator.

Indicators with poor kappa scores $(<0.4)$ for intra-rater reliability were no. 17 (the most comfortable position during second-stage labour), no. 31, and no. 33 (mother or infant readmitted within 30 days of discharge). Intra-rater reliability kappa scores that were incalculable or 0 were found for ten indicators: no. 3 , no. 4 , and no. 6 (assessment during second-stage labour), no. 12 (Apgar score less than 7 at 5 min after birth), no. 14, no. 


\begin{tabular}{|c|c|c|}
\hline Characteristics & Median or number $(\%)$ & Min-Max \\
\hline \multicolumn{3}{|l|}{ Mothers } \\
\hline Age (years) & 31 & $19-44$ \\
\hline Total blood loss (mL) & 319 & $52-1863$ \\
\hline Body mass index before pregnancy $\left(\mathrm{kg} / \mathrm{m}^{2}\right)$ & 19.7 & $15.3-28.7$ \\
\hline Body mass index at delivery $\left(\mathrm{kg} / \mathrm{m}^{2}\right)$ & 23.9 & $18.5-31.2$ \\
\hline Woman height $(\mathrm{cm})$ & 158 & $147-174$ \\
\hline Duration of delivery (hours:minutes) & 6:29 & $1: 18-34: 15$ \\
\hline Pregnancy week when a woman desired to delivery in primary midwifery care & 28 & $18-39$ \\
\hline Hospitalization (length of stay) (day) & 6 & $5-16$ \\
\hline Nulliparous & $146(42 \%)$ & \\
\hline Multiparous & $201(58 \%)$ & \\
\hline \multirow{2}{*}{ Cigarette use during pregnancy } & $14(4 \%)$ & \\
\hline & $1(0 \%)$ & \\
\hline \multicolumn{3}{|l|}{ Infants } \\
\hline Birth weight (g) & 2,978 & $2,244-3,968$ \\
\hline Birth height $(\mathrm{cm})$ & 49 & $44-53$ \\
\hline Gestational age (weeks) & 39 & $37-41$ \\
\hline Cord blood arterial acidity $(\mathrm{pH})$ & 7.3 & $7.1-7.5$ \\
\hline Base excess (BE) (mmol/L) & -4.7 & $-14.6-5.7$ \\
\hline Carbon dioxide tension $\left(\mathrm{PCO}_{2}\right)(\mathrm{mmHg})$ & 38.9 & $14.8-72.7$ \\
\hline Oxygen tension $\left(\mathrm{PO}_{2}\right)(\mathrm{mmHg})$ & 19.1 & $9.4-30.2$ \\
\hline Infant female & $160(46 \%)$ & \\
\hline Foetal or neonatal death & $0(0 \%)$ & \\
\hline
\end{tabular}

Table 2. Characteristics of the participating mothers and infants $(n=347)$.

15 , no. 26, no. 27 (a fall during hospitalization), no. 34 (screening for antenatal or postnatal depression), and no. 35 (complete medical records based on all quality indicators). Indicators with a poor kappa score $(<0.40)$ for inter-rater reliability were no. 4 and no. 5 (assessment during first-stage labour). Inter-rater reliability kappa scores that were incalculable or 0 were found for ten indicators: nos. 6, 12, 14, 20, 26, 27, 28, 30, 31, 34, and 35 .

The median (range) score for positive agreement intra-rater reliability was $0.95(0.33-1.00)$ and for negative agreement intra-rater reliability was $0.99(0.67-1.00)$. The lowest positive score $(0)$ was found for the following indicators: no. 4 , no. 6 , no. 14 , no. 15 , and no. 33 ; the second-lowest positive score was 0.33 for no. 31 . The lowest negative agreement score (0.33) was for no. 17 . The median (range) score for positive agreement inter-rater reliability was $0.91(0.25-1.00)$ and for negative agreement inter-rater reliability was $0.98(0.57-1.00)$. The lowest positive score ( 0 ) was found for no. 6 , no. 14 , and no. 31 . The second-lowest negative score $(0.25)$ was for no. 4. The lowest negative agreement score (0.57) was for no. 2 (birth plan) and no. 17.

Three indicators (no. 17, no 31, and no. 31) with poor intra-rater kappa scores showed positive/negative agreement scores of $0.94 / 0.33,0.33 / 0.95$, and $0 / 0.97$, respectively. Two indicators (no. 4 and no 5 ) with poor inter-rater kappa scores showed positive/negative agreement scores of $0.25 / 0.92$ and $0.68 / 0.61$, respectively.

\section{Discussion}

By extracting the necessary information from 347 existing medical records for mothers and children before assessing quality, we assessed the multifaceted applicability of 35 care quality indicators for planned hospital birth among woman with low-risk pregnancy. The feasibility of 29 indicators was high and 33 indicators showed a high potential for improvement. Although some indicators showed low kappa scores, the high agreement scores indicated that the reliability of these indicators was acceptable. With some caveats, the present practice test supported the applicability of these quality indicators, which were previously developed in Japan.

This is the first study to show the applicability of care quality indicators for planned hospital birth for women with low-risk pregnancy. However, the applicability of these quality indicators for real-world practice needs fully testing before they are disseminated. No studies have tested the applicability of care quality indicators for birth in low-risk women using the consensus method ${ }^{30-32}$. Previous studies that have tested the applicability of quality indicators in general have not fully shared an unified terminology $y^{24,25,33,34}$. In the present study, we tested quality indicator applicability in terms of feasibility, potential for improvement, and reliability.

We found that most indicators were feasible as 29 indicators with feasibility had less than $25 \%$ of missing data for an indicator score. However, there was concern about the feasibility of the following six indicators owing to the high proportion ( $>25 \%$ ) of missing data: no. 14 , no. 15 , no. 26 , no. 28 , no. 30 , and no. 31 . These indicators showed low feasibility because no data were recorded in the medical charts. If data are prospectively collected with a defined format, there is a lower likelihood of missing or ambiguous data ${ }^{35,36}$. The present practice test revealed that two indicators (no. 3 and no. 4) had a low improvement potential (score of over 90\%). This was because these two indicators were practiced almost routinely. We consider this a "ceiling effect": a phenomenon 


\begin{tabular}{|c|c|c|c|c|c|c|c|}
\hline No & Quality indicator & Definition of denominator & Denominator (n) & Missing data (n) & Missing data (\%) & Numerator (n) & Adherence (\%) \\
\hline 1 & Birth class & Primipara & 146 & 23 & 15.8 & 104 & 71.2 \\
\hline 2 & Birth plan & Pregnant women & 347 & 78 & 22.5 & 269 & 77.5 \\
\hline 3 & $\begin{array}{l}\text { Antibiotic prophylaxis for group B } \\
\text { streptococcus infection }\end{array}$ & $\begin{array}{l}\text { Women with group B streptococcus } \\
\text { infections at 33-37 weeks' gestation }\end{array}$ & 41 & 2 & 4.9 & 38 & $92.7^{\mathrm{b}}$ \\
\hline 4 & $\begin{array}{l}\text { Initial assessment of labour risk at } \\
\text { admission }\end{array}$ & $\begin{array}{l}\text { Pregnant women admitted for } \\
\text { delivery at hospital }\end{array}$ & 347 & 0 & 0 & 332 & $95.7^{\mathrm{b}}$ \\
\hline 5 & Assessment during first stage labour & $\begin{array}{l}\text { Pregnant women admitted during } \\
\text { first labour }\end{array}$ & 342 & 4 & 1.2 & 161 & 47.1 \\
\hline 6 & Assessment during first stage labour & $\begin{array}{l}\text { Pregnant women admitted for } \\
\text { delivery at hospital }\end{array}$ & 347 & 6 & 1.7 & 2 & 0.6 \\
\hline 7 & $\begin{array}{l}\text { Spontaneous vaginal birth in a } \\
\text { midwifery unit }\end{array}$ & $\begin{array}{l}\text { Women planning childbirth at } \\
\text { midwifery unit in hospital during } \\
\text { second trimester }\end{array}$ & 388 & 0 & 0 & 276 & 71.1 \\
\hline 8 & Caesarean section & Pregnant women & 347 & 0 & 0 & 7 & 2.0 \\
\hline 9 & Spontaneous vaginal delivery & Pregnant women & 347 & 0 & 0 & 276 & 79.5 \\
\hline 10 & Instrument delivery & Pregnant women & 347 & 0 & 0 & 24 & 6.9 \\
\hline 11 & Labour induction & Pregnant women & 347 & 0 & 0 & 56 & 16.1 \\
\hline 12 & $\begin{array}{l}\text { Apgar score less than } 7 \text { at } 5 \text { min } \\
\text { after birth }\end{array}$ & Infants & 347 & 0 & 0 & 2 & 0.6 \\
\hline 13 & Birth injuries & Living infants & 347 & 11 & 3.2 & 10 & 2.9 \\
\hline 14 & Respiratory support & Infants with asphyxia after birth & 18 & 5 & $27.8^{\mathrm{a}}$ & 1 & 5.6 \\
\hline 15 & $\begin{array}{l}\text { Japanese Neonatal Resuscitation } \\
\text { Algorithm }\end{array}$ & $\begin{array}{l}\text { Infants evaluated to offer the } \\
\text { necessary resuscitation in the first } \\
\text { minutes after birth }\end{array}$ & 24 & 7 & $29.2^{\mathrm{a}}$ & 17 & 70.8 \\
\hline 16 & Early skin-to-skin contact & $\begin{array}{l}\text { Pregnant women wished to make } \\
\text { early skin-to-skin contact with their } \\
\text { babies soon after birth in secure } \\
\text { surroundings }\end{array}$ & 347 & 60 & 17.3 & 273 & 78.7 \\
\hline 17 & $\begin{array}{l}\text { Comfortable positions throughout } \\
\text { second stage labour }\end{array}$ & $\begin{array}{l}\text { Women confirmed the safety for } \\
\text { baby in comfortable positions }\end{array}$ & 303 & 63 & 20.8 & 226 & 74.6 \\
\hline 18 & Perineal tear and no perineorrhaphy & Women had vaginal deliveries & 340 & 0 & 0 & 130 & 38.2 \\
\hline 19 & Second degree perineal laceration & Woman had vaginal deliveries & 340 & 0 & 0 & 72 & 21.2 \\
\hline 20 & $\begin{array}{l}\text { Third or fourth degree perineal } \\
\text { laceration }\end{array}$ & Woman had vaginal deliveries & 340 & 0 & 0 & 4 & 1.2 \\
\hline 21 & $\begin{array}{l}\text { Postpartum haemorrhage more } \\
\text { than } 500 \mathrm{~g} \text { within } 2 \mathrm{~h} \text { of birth }\end{array}$ & Woman had vaginal deliveries & 338 & 2 & 0.6 & 66 & 19.5 \\
\hline 22 & $\begin{array}{l}\text { Uterotonics for the prevention of } \\
\text { postpartum haemorrhage }\end{array}$ & Woman had vaginal deliveries & 340 & 0 & 0 & 131 & 38.5 \\
\hline 23 & $\begin{array}{l}\text { Admission to paediatrics depart- } \\
\text { ment within a week after birth }\end{array}$ & $\begin{array}{l}\text { Infants without antenatally congeni- } \\
\text { tal anomalies }\end{array}$ & 347 & 0 & 0 & 60 & 17.3 \\
\hline 24 & $\begin{array}{l}\text { Feeding only breast milk at the time } \\
\text { of discharge from the hospital }\end{array}$ & $\begin{array}{l}\text { Infants who didn't admit to pae- } \\
\text { diatrics department or didn't need } \\
\text { to supply formula with medical } \\
\text { evidence }\end{array}$ & 287 & 0 & 0 & 175 & 61.0 \\
\hline 25 & $\begin{array}{l}\text { Formula supplementation without } \\
\text { medical rationale during hospi- } \\
\text { talization }\end{array}$ & $\begin{array}{l}\text { Infants who didn't admit to pae- } \\
\text { diatrics department or didn't need } \\
\text { to supply formula with medical } \\
\text { evidence }\end{array}$ & 281 & 0 & 0 & 56 & 19.9 \\
\hline 26 & $\begin{array}{l}\text { Peer review of severe adverse events } \\
\text { with medical staff }\end{array}$ & $\begin{array}{l}\text { Women of infant with severe } \\
\text { adverse events }\end{array}$ & 10 & 10 & $100^{\mathrm{a}}$ & 0 & 0.0 \\
\hline 27 & $\begin{array}{l}\text { Women having a fall during their } \\
\text { hospitalization }\end{array}$ & $\begin{array}{l}\text { Total number of days while women } \\
\text { admitted for birth }\end{array}$ & 2,145 & 0 & 0 & 0 & 0.0 \\
\hline 28 & $\begin{array}{l}\text { Women having a review of their } \\
\text { childbirth experience and support } \\
\text { with the midwives and other staff } \\
\text { who assisted at the birth }\end{array}$ & Pregnant women & 347 & 344 & $99.1^{\mathrm{a}}$ & 3 & 0.9 \\
\hline 29 & $\begin{array}{l}\text { Women switched to receive care } \\
\text { provided primarily by obstetricians } \\
\text { from midwifery ward }\end{array}$ & Pregnant women & 347 & 0 & 0 & 78 & 22.5 \\
\hline 30 & $\begin{array}{l}\text { Women received cessation counsel- } \\
\text { ling intervention }\end{array}$ & \begin{tabular}{|l|} 
Women who identified a tobacco \\
user or passive smoker and who \\
didn't transport to or from the other \\
hospital
\end{tabular} & 14 & 6 & $42.9^{\mathrm{a}}$ & 4 & 28.6 \\
\hline 31 & $\begin{array}{l}\text { Infants administered vitamin K } \\
\text { three times by one month after birth }\end{array}$ & $\begin{array}{l}\text { Infants who didn't admit to paediat- } \\
\text { rics department }\end{array}$ & 287 & 282 & $98.3^{\mathrm{a}}$ & 4 & 1.4 \\
\hline 32 & $\begin{array}{l}\text { Feeding only breast milk at the } \\
\text { time of the health examination for } \\
\text { children of } 1 \text { month of age }\end{array}$ & $\begin{array}{l}\text { Infants who didn't admit to pae- } \\
\text { diatrics department or didn't need } \\
\text { to supply formula with medical } \\
\text { evidence }\end{array}$ & 287 & 0 & 0 & 219 & 76.3 \\
\hline
\end{tabular}




\begin{tabular}{|c|c|c|c|c|c|c|c|}
\hline No & Quality indicator & Definition of denominator & Denominator (n) & Missing data (n) & Missing data (\%) & Numerator (n) & Adherence (\%) \\
\hline 33 & $\begin{array}{l}\text { Women or infants readmitted } \\
\text { within } 30 \text { days of discharge }\end{array}$ & $\begin{array}{l}\text { Total number of women and infants } \\
\text { hospitalized for birth }\end{array}$ & $794 \|$ & 0 & 0 & 8 & 1.2 \\
\hline 34 & $\begin{array}{l}\text { Women being screened for antena- } \\
\text { tal or postnatal depression using a } \\
\text { validated questionnaire }\end{array}$ & Pregnant women & 347 & 0 & 0 & 0 & 0.0 \\
\hline 35 & $\begin{array}{l}\text { Women and infants having com- } \\
\text { plete medical records based on all } \\
\text { quality indicator }\end{array}$ & $\begin{array}{l}\text { Women and infants who didn't } \\
\text { admitting within } 24 \mathrm{~h}\end{array}$ & 347 & 0 & 0 & 0 & 0.0 \\
\hline
\end{tabular}

Table 3. Scores for the 35 quality indicators: feasibility and improvement potential. "Unfeasibility" was defined as missing data for $>25 \%$ of participants (denominator). "Low opportunity for quality improvement" was defined as indicator scores $\geq 90 \%$.

\begin{tabular}{|c|c|c|c|c|c|c|}
\hline \multirow[b]{2}{*}{ No } & \multicolumn{3}{|c|}{ Intra-rater reliability $n=40$} & \multicolumn{3}{|c|}{ Inter-rater reliability $n=\mathbf{4 0}$} \\
\hline & Kappa & Positive agreement & Negative agreement & Kappa & Positive agreement & Negative agreement \\
\hline 1 & 1 & 1 & 1 & 0.72 & 0.91 & 0.81 \\
\hline 2 & 0.63 & 0.96 & 0.67 & 0.44 & 0.85 & 0.57 \\
\hline 3 & - & 1 & - & 1 & 1 & 1 \\
\hline 4 & 0 & 0 & 0.96 & 0.17 & 0.25 & 0.92 \\
\hline 5 & 0.68 & 0.84 & 0.84 & 0.29 & 0.68 & 0.61 \\
\hline 6 & 0 & 0 & 0.97 & 0 & 0 & 0.97 \\
\hline 7 & 1 & 1 & 1 & 1 & 1 & 1 \\
\hline 8 & 1 & 1 & 1 & 1 & 1 & 1 \\
\hline 9 & 0.86 & 0.97 & 0.89 & 0.79 & 0.99 & 0.80 \\
\hline 10 & 1 & 1 & 1 & 1 & 1 & 1 \\
\hline 11 & 1 & 1 & 1 & 0.93 & 0.94 & 0.98 \\
\hline 12 & - & - & 1 & - & - & 1 \\
\hline 13 & 1 & 1 & 1 & 0.79 & 0.80 & 0.99 \\
\hline 14 & 0 & 0 & 0.86 & 0 & 0 & 0.67 \\
\hline 15 & 0 & 0 & 0.86 & 1 & 1 & 1 \\
\hline 16 & 0.66 & 0.92 & 0.74 & 0.55 & \begin{tabular}{|l|}
0.88 \\
\end{tabular} & 0.67 \\
\hline 17 & 0.3 & 0.94 & 0.33 & 0.49 & 0.91 & 0.57 \\
\hline 18 & \begin{tabular}{|l|}
0.79 \\
\end{tabular} & 0.80 & 0.99 & 0.88 & \begin{tabular}{|l|}
0.89 \\
\end{tabular} & 0.99 \\
\hline 19 & 0.95 & 0.97 & 0.98 & 1 & 1 & 1 \\
\hline 20 & 1 & 1 & 1 & - & - & 1 \\
\hline 21 & 1 & 1 & 1 & 0.93 & 0.94 & 0.98 \\
\hline 22 & 0.63 & 0.77 & 0.86 & 0.4 & \begin{tabular}{|l|}
0.68 \\
\end{tabular} & 0.71 \\
\hline 23 & \begin{tabular}{|l|}
0.93 \\
\end{tabular} & 0.95 & 0.98 & 0.87 & 0.90 & 0.97 \\
\hline 24 & 0.9 & 0.95 & 0.95 & 0.85 & 0.93 & 0.92 \\
\hline 25 & \begin{tabular}{|l|}
0.78 \\
\end{tabular} & 0.82 & 0.95 & 0.83 & 0.88 & 0.95 \\
\hline 26 & - & - & 1 & - & - & 1 \\
\hline 27 & - & - & 1 & - & - & 1 \\
\hline 28 & 1 & 1 & 1 & - & - & 1 \\
\hline 29 & \begin{tabular}{|l|}
0.83 \\
\end{tabular} & 0.88 & 0.95 & 0.67 & \begin{tabular}{|l|}
0.79 \\
\end{tabular} & 0.88 \\
\hline 30 & 1 & 1 & 1 & - & - & 1 \\
\hline 31 & 0.3 & 0.33 & 0.95 & 0 & 0 & 0.95 \\
\hline 32 & 1 & 1 & 1 & 1 & 1 & 1 \\
\hline 33 & -0.03 & 0 & 0.97 & 1 & 1 & 1 \\
\hline 34 & - & - & 1 & - & - & 1 \\
\hline 35 & - & - & 1 & - & - & 1 \\
\hline
\end{tabular}

Table 4. Results for intra-rater and inter-rater reliability. “-” indicates an incalculable positive agreement or negative agreement or kappa score.

in which the scores for the quality indicator are near their maximum value and thus impossible to substantially increase. It is also very difficult to evaluate quality improvement or detect differences between the measured scores for such indicators over time and in other hospitals. The present results were based on only two hospitals that actively cooperated with the practice test and may have been conscious about care quality. At present, we 
cannot be certain that these two indicators showed a ceiling effect and that their measurement was invalid. Accordingly, adherence to the indicators should be examined in a large range of settings to determine whether they should be retained or rejected.

Some of intra-rater and inter-rater reliability showed paradoxical results that low kappa score with high level of agreement ${ }^{26,37}$. Cohen' kappa is generally used as a method of reproducibility evaluation. The aim of this study is to assess the reliability of quality indicators, that is the inter- and intra-rater reproducibility. Cohen' kappa is generally used as a method of reproducibility evaluation. However, when the distribution of responses is biased, there are paradoxical cases that kappa score shows low even if the actual proportion of agreement is high, namely. Therefore, we used kappa as primary measure of reliability (the inter- and intra-rater reproducibility), and secondarily used the positive/negative agreement proposed by de Vet et al., considering the possibility of such paradox. Based on both scores of kappa and agreement, quality indicators with low kappa score do not always mean low reliability (reproducibility).

Quality indicator scores were 0 or incalculable kappa scores were close to 0 or 100 . All indicators with low kappa scores had positive or negative agreement scores $>0.5$ in this study. A low kappa score did not necessarily reflect low reliability for a quality indicator. Therefore, we used positive and negative agreement scores together and assessed reliability considering both scores of them. Agreement scores of 0 were found for no. 4 , no. 6, no. 14 , no. 15 , no. 31 , and no. 33 , and reflect the very small or large number of participants to which those indicators related. Excluding indicators with an agreement score of 0 , indicators with the lowest intra-rater reliability agreement score were no. 31 (positive) and no. 17 (negative). The lowest agreement score for inter-rater reliability was for no. 4 (positive) and for no. 2 and no. 17 (both negative), which may reflect the difficulty of identifying relevant data from the medical records. If clinical staff were given advance notification of surveys of quality indicators and prospective data collection, this may increase adherence to the indicators and onsite data recording, which would improve indicator reliability. An additional reason for low reliability was the composite nature of the indicators (e.g., no. 4). Some indicators comprise two or more individual component measures ${ }^{23,38}$, and so may be characterized by a greater risk of disagreement. However, such composite indicators are meaningful only when all individual components are satisfied; individual itemization would reduce their significance. Therefore, the indicators need to be used as they are, with full knowledge of the risk of low reliability for retrospective record reviews.

We acknowledge several limitations. First, the practice test was conducted in only two hospitals with perinatal medical centres. Both hospitals had enough medical facilities and staff to provide onsite advanced obstetric care for high-risk problems and also midwife-led continuity care. The high level of care in the two participating hospitals may have affected the present findings; data from lower-level hospitals might show more missing data, resulting in lower feasibility according to the criteria. Indicators measured in lower-level hospitals may not show the $\geq 90 \%$ or higher adherence found in the present study, and may show greater potential for improvement. Additionally, reliability would be lower for low-quality medical records. Second, the applicability that we examined was limited to feasibility, improvement potential, and reliability. We did not test acceptability and predictive validity (i.e., whether indicators are related to clinical outcomes). However, our multidisciplinary panel evaluated and confirmed validity and acceptability during the development process ${ }^{19,20}$. Adverse maternal or perinatal outcomes for women with low-risk pregnancy are rare, so predictive validity is difficult to establish. Third, although the set of indicators was systematically developed based on existing international practice guidelines and quality indicators, it was only tested in Japan and may not be directly applicable to other countries in its present form. The process used in this study may be useful to test applicability in other settings ${ }^{39}$.

To conclude, the present study showed that the 35 quality indicators for low-risk women planning hospital birth could, with some caveats, be applicable to real-world clinical practice.

\section{Data availability}

No sharing data are available.

Received: 27 January 2020; Accepted: 7 July 2020

Published online: 27 July 2020

\section{References}

1. Birthplace in England Collaborative Group, Brocklehurst, P. et al. Perinatal and maternal outcomes by planned place of birth for healthy women with low risk pregnancies: the Birthplace in England national prospective cohort study. BMJ 343, d7400. https:// doi.org/10.1136/bmj.d7400 (2011).

2. de Jonge, A. et al. Perinatal mortality and morbidity up to 28 days after birth among 743070 low-risk planned home and hospital births: a cohort study based on three merged national perinatal databases. BJOG 122, 720-728. https://doi.org/10.1111/14710528.13084 (2015).

3. Hiraizumi, Y. \& Suzuki, S. Perinatal outcomes of low-risk planned home and hospital births under midwife-led care in Japan. J. Obstet. Gynaecol. Res. 39, 1500-1504. https://doi.org/10.1111/jog.12094 (2013).

4. Homer, C. S. et al. Birthplace in New South Wales, Australia: an analysis of perinatal outcomes using routinely collected data. BMC Pregnancy Childbirth. 14, 206. https://doi.org/10.1186/1471-2393-14-206 (2014).

5. van der Kooy, J. et al. Planned home compared with planned hospital births in the Netherlands: intrapartum and early neonatal death in low-risk pregnancies. Obstet. Gynecol. 118, 1037-1046. https://doi.org/10.1097/AOG.0b013e3182319737 (2011).

6. Sandall, J., McCandlish, R. \& Bick, D. Place of birth. Midwifery 28, 547. https://doi.org/10.1016/j.midw.2012.08.003 (2012).

7. Sandall, J., Soltani, H., Gates, S., Shennan, A. \& Devane, D. Midwife-led continuity models versus other models of care for childbearing women. Cochrane Database Syst. Rev. 4, Cd004667. https://doi.org/10.1002/14651858.CD004667.pub5 (2016).

8. Chaillet, N. et al. A cluster-randomized trial to reduce cesarean delivery rates in Quebec. N. Engl. J. Med. 372, 1710-1721. https ://doi.org/10.1056/NEJMoa1407120 (2015). 
9. Dunn, S. et al. The use of a quality indicator to reduce elective repeat Caesarean section for low-risk women before 39 weeks' gestation: the Eastern Ontario experience. J. Obstet. Gynaecol. Can. 35, 306-316. https://doi.org/10.1016/s1701-2163(15)30957-9 (2013).

10. Friedman, A. M., Ananth, C. V., Prendergast, E., D’Alton, M. E. \& Wright, J. D. Evaluation of third-degree and fourth-degree laceration rates as quality indicators. Obstet. Gynecol. 125, 927-937. https://doi.org/10.1097/aog.0000000000000720 (2015).

11. Campbell, S. M., Braspenning, J., Hutchinson, A. \& Marshall, M. Research methods used in developing and applying quality indicators in primary care. Qual. Saf. Health Care 11, 358-364. https://doi.org/10.1136/qhc.11.4.358 (2002).

12. Martin Lawrence, F. O. Indicators of quality in health care. Eur. J. Gen. Pract. https://doi.org/10.3109/13814789709160336 (1997).

13. Boulkedid, R., Alberti, C. \& Sibony, O. Quality indicator development and implementation in maternity units. Best Pract. Res. Clin. Obstet. Gynaecol. 27, 609-619. https://doi.org/10.1016/j.bpobgyn.2013.04.001 (2013).

14. Bunch, K. J., Allin, B., Jolly, M., Hardie, T. \& Knight, M. Developing a set of consensus indicators to support maternity service quality improvement: using Core Outcome Set methodology including a Delphi process. BJOG 125, 1612-1618. https://doi. org/10.1111/1471-0528.15282 (2018).

15. Escuriet, R. et al. Assessing the performance of maternity care in Europe: a critical exploration of tools and indicators. BMC Health Serv. Res. 15, 491. https://doi.org/10.1186/s12913-015-1151-2 (2015).

16. Pazandeh, F., Huss, R., Hirst, J., House, A. \& Baghban, A. A. An evaluation of the quality of care for women with low risk pregnanacy: the use of evidence-based practice during labour and childbirth in four public hospitals in Tehran. Midwifery 31, 1045-1053. https://doi.org/10.1016/j.midw.2015.07.003 (2015).

17. Ministry of Health, Labour and Welfare, Japan. Vital statistics of Japan 2017. accessed 15 July 2020. https://www.mhlw.go.jp/touke i/list/81-1.html (2017).

18. Ministry of Health, Labour and Welfare, Japan. Summary of Examples of Health Administration Reports (medical professionals at work) in 2019. accessed 15 July 2020. https://www.mhlw.go.jp/toukei/saikin/hw/eisei/18/ (2019).

19. Ueda, K., Ohtera, S., Kaso, M. \& Nakayama, T. Development of quality indicators for low-risk labor care provided by midwives using a RAND-modified Delphi method. BMC Pregnancy Childbirth 17, 315. https://doi.org/10.1186/s12884-017-1468-4 (2017).

20. Ueda, K., Kaso, M., Ohtera, S. \& Nakayama, T. Updating quality indicators for low-risk labour care in Japan using current clinical practice guidelines: a modified Delphi method. BMJ Open 9, e023595. https://doi.org/10.1136/bmjopen-2018-023595 (2019).

21. Campbell, S. M., Braspenning, J., Hutchinson, A. \& Marshall, M. N. Research methods used in developing and applying quality indicators in primary care. BMJ 326, 816-819. https://doi.org/10.1136/bmj.326.7393.816 (2003).

22. Grol, R., Baker, R. \& Moss, F. Quality Improvement Research: Understanding the Science of Change in Health Care 6-28 (BMJ Publish Group, London, 2004).

23. National Quality Forum. Measure Evaluation Criteria and Guidance for Evaluating Measures for Endorsement. accessed 15 July 2020. https://www.qualityforum.org/Measuring_Performance/Submitting_Standards/Measure_Evaluation_Criteria.aspx (2016).

24. Schouten, J. A. et al. Quality of antibiotic use for lower respiratory tract infections at hospitals: (how) can we measure it?. Clin Infect Dis. 41, 450-460. https://doi.org/10.1086/431983 (2005).

25. Hommel, I., van Gurp, P. J., Tack, C. J., Wollersheim, H. \& Hulscher, M. E. Perioperative diabetes care: development and validation of quality indicators throughout the entire hospital care pathway. BMJ Qual. Saf. 25, 525-534. https://doi.org/10.1136/bmjqs -2015-004112 (2016).

26. de Vet, H. C. W., Mokkink, L. B., Terwee, C. B., Hoekstra, O. S. \& Knol, D. L. Clinicians are right not to like Cohen's к. BMJ 346, f2125. https://doi.org/10.1136/bmj.f212589 (2013).

27. Landis, J. R. \& Koch, G. G. The measurement of observer agreement for categorical data. Biometrics 33, 159-174 (1977).

28. Harris, P. A. et al. Research electronic data capture (REDCap)—a metadata-driven methodology and workflow process for providing translational research informatics support. J. Biomed. Inform. 42, 377-381. https://doi.org/10.1016/j.jbi.2008.08.010 (2009).

29. Brown, L. D. et al. Interval estimation for a binomial proportion. Stat. Sci. 16, 101-133 (2001).

30. Boesveld, I. C. et al. An approach to assessing the quality of birth centres results of the Dutch birth centre study. Midwifery 66, 36-48. https://doi.org/10.1016/j.midw.2018.07.008 (2018).

31. Reszel, J. et al. Use of a maternal newborn audit and feedback system in Ontario: a collective case study. BMJ Qual. Saf. 28, 635-644. https://doi.org/10.1136/bmjqs-2018-008354 (2019).

32. Sprague, A. E. et al. Measuring quality in maternal-newborn care: developing a clinical dashboard. J. Obstet. Gynaecol. Can. 35, 29-38 (2013).

33. Campbell, S. M. et al. Quality assessment for three common conditions in primary care: validity and reliability of review criteria developed by expert panels for angina, asthma and type 2 diabetes. Qual. Saf. Health Care 11, 125-130 (2002).

34. van den Bosch, C. M. et al. Applicability of generic quality indicators for appropriate antibiotic use in daily hospital practice: a cross-sectional point-prevalence multicenter study. Clin. Microbiol. Infect. 22, 8881-8889. https://doi.org/10.1016/j.cmi.2016.07.011 (2016).

35. Fleischmann, R., Decker, A. M., Kraft, A., Mai, K. \& Schmidt, S. Mobile electronic versus paper case report forms in clinical trials: a randomized controlled trial. BMC Med. Res. Methodol. 17, 153. https://doi.org/10.1186/s12874-017-0429-y (2017).

36. Wollersheim, H. et al. Clinical indicators: development and applications. Neth. J. Med. 65, 15-22 (2007).

37. Streiner, D. L., Norman, G. R. \& Cairney, J. Health Measurement Scales: A Practical Guide to Their Development and Use 5th edn, 172-178 (Oxford University Press, Oxford, 2016).

38. Profit, J. et al. Improving benchmarking by using an explicit framework for the development of composite indicators: an example using pediatric quality of care. Implement. Sci. 5, 13. https://doi.org/10.1186/1748-5908-5-13 (2010).

39. Marshall, M. N. et al. Can health care quality indicators be transferred between countries?. Qual. Saf. Health Care 12, 8-12 (2003).

\section{Acknowledgements}

We are grateful to Sachie Nishi and Fumitomo Nishimura for collaboration and support in implementing our study and to Tomoko Terai, Miyuki Nakagami, Hiromi Kuze, Natsuki Nojima, Nozomi Niwa, Aya Hisashi, and Mai Takeshita for data collection and support in study implementation. This work was supported by the Ministry of Education, Culture, Sports, Science and Technology (MEXT) KAKENHI Grant Numbers JP26870745 and JP18K17591. We were supported by Project Promoting Clinical Trials for Development New Drugs/Support Program for Biostatisticians from the Japan Agency for Medical Research and Development 19lk0201061t0004. We thank the Edanz Group (https://en-author-services.edanzgroup.com/) for editing a draft of this manuscript.

\section{Author contributions}

K.U., T.S., Y.T., T.I., and T.N. participated in the conception and design of the study and recruited participants. K.U. and T.S. collected data. K.U., T.Y., and T.N. designed and performed the analysis. K.U. wrote the initial manuscript text and prepared Tables 1-4, Fig. 1, and the supplementary information. All authors reviewed and revised the manuscript, contributed to the interpretation of results and critical review of the manuscript, and approved the final version of the manuscript for submission. 


\section{Competing interests}

The authors declare no competing interests.

\section{Additional information}

Supplementary information is available for this paper at https://doi.org/10.1038/s41598-020-69346-8.

Correspondence and requests for materials should be addressed to K.U.

Reprints and permissions information is available at www.nature.com/reprints.

Publisher's note Springer Nature remains neutral with regard to jurisdictional claims in published maps and institutional affiliations.

Open Access This article is licensed under a Creative Commons Attribution 4.0 International License, which permits use, sharing, adaptation, distribution and reproduction in any medium or format, as long as you give appropriate credit to the original author(s) and the source, provide a link to the Creative Commons license, and indicate if changes were made. The images or other third party material in this article are included in the article's Creative Commons license, unless indicated otherwise in a credit line to the material. If material is not included in the article's Creative Commons license and your intended use is not permitted by statutory regulation or exceeds the permitted use, you will need to obtain permission directly from the copyright holder. To view a copy of this license, visit http://creativecommons.org/licenses/by/4.0/.

(C) The Author(s) 2020 